OPEN ACCESS

Edited by:

Markus Paulus,

Ludwig Maximilian University of Munich, Germany

Reviewed by:

Regula Neuenschwander, University of Bern, Switzerland Daniela Kloo,

University of Salzburg, Austria

${ }^{*}$ Correspondence:

Florian A. Enge/

florian.enge/@issw.uni-heidelberg.de

Specialty section:

This article was submitted to Developmental Psychology, a section of the journal

Frontiers in Psychology

Received: 09 November 2018

Accepted: 25 March 2019

Published: 10 April 2019

Citation:

Jarraya S, Wagner $M$, Jarraya $M$

and Engel FA (2019) 12 Weeks of Kindergarten-Based Yoga Practice

Increases Visual Attention,

Visual-Motor Precision and Decreases

Behavior of Inattention

and Hyperactivity in 5-Year-Old

Children. Front. Psychol. 10:796.

doi: 10.3389/fpsyg.2019.00796

\section{Weeks of Kindergarten-Based Yoga Practice Increases Visual Attention, Visual-Motor Precision and Decreases Behavior of Inattention and Hyperactivity in 5-Year-Old Children}

\author{
Sana Jarraya ${ }^{1}$, Matthias Wagner ${ }^{2}$, Mohamed Jarraya' ${ }^{1}$ and Florian A. Engel ${ }^{3 *}$ \\ ${ }^{1}$ Research Unit, High Institute of Sport and Physical Education, University of Sfax, Sfax, Tunisia, ${ }^{2}$ Department of Sport \\ Science, Bundeswehr University Munich, Neubiberg, Germany, ${ }^{3}$ Department Movement and Training Science, Institute \\ of Sport and Sport Science, Heidelberg University, Heidelberg, Germany
}

The present study assesses the impact of Kindergarten-based yoga on cognitive performance, visual-motor coordination, and behavior of inattention and hyperactivity in 5-year-old children. In this randomized controlled trial, 45 children (28 female; 17 male; $5.2 \pm 0.4$ years) participated. Over 12 weeks, 15 children performed Hathayoga twice a week for $30 \mathrm{~min}$, another 15 children performed generic physical education (PE) twice a week for $30 \mathrm{~min}$, and 15 children performed no kind of physical activities, serving as control group (CG). Prior to $\left(T_{0}\right)$ and after 12 weeks $\left(T_{1}\right)$, all participants completed Visual Attention and Visuomotor Precision subtests of Neuropsychological Evaluation Battery and teachers evaluated children's behavior of inattention and hyperactivity with the Attention-Deficit/Hyperactivity Disorder (ADHD) Rating Scale-IV. At $T_{0}$, no significant differences between groups appeared. Repeated measures analysis of variance revealed that following Bonferroni-Holm corrections yoga, in comparison to PE and CG, had a significant positive impact on the development on behavior of inattention and hyperactivity. Further, yoga has a significant positive impact on completion times in two visumotor precision tasks in comparison to PE. Finally, results indicate a significant positive effect of yoga on visual attention scores in comparison to CG. 12 weeks of Kindergarten-based yoga improves selected visual attention and visual-motor precision parameters and decreases behavior of inattention and hyperactivity in 5-year-old children. Consequently, yoga represents a sufficient and cost-benefit effective exercise which could enhance cognitive and behavioral factors relevant for learning and academic achievement among young children.

Keywords: behavior modification, cognition, executive functions, preschool, exercise intervention 


\section{INTRODUCTION}

As an important basis for academic achievement in children and adolescents, adequate cognitive functions are suggested (Duncan et al., 2007; McClelland et al., 2013). Whereas, cognitive functions are defined as an individual's mental processes, including memory, attention, learning, problem solving, reasoning, and decision-making (Matlin, 2009).

Recently, a growing body of literature appears examining the effects of acute and chronic physical activity in young and preadolescent children and its impacts on cognitive and executive functions as well as on academic achievement (Verburgh et al., 2014; Ludyga et al., 2016; de Greeff et al., 2018; Singh et al., 2018). Whereas, the association between executive functions and academic achievement is consistently demonstrated and emphasized (Blair and Raver, 2015). The concept of executive functions comprises several cognitive functions and refers to at least three interrelated cognitive functions (Miyake et al., 2000): inhibition, shifting, and updating (for overview, see Diamond, 2013). In this context, recent research demonstrated that physical activity can lead to improved cognitive and executive functions and enhanced academic achievement in young students (Sattelmair and Ratey, 2009; Fedewa and Ahn, 2011; Verburgh et al., 2014; de Greeff et al., 2018; Oberer et al., 2018). More precisely, a recent meta-analysis showed that physical activity has a small positive effect on school engagement in students aged 6-15 years (Owen et al., 2016). Since school engagement is a crucial factor determining academic performance (Perry et al., 2010), this demonstrates the potential of physical activity for academic achievement. Furthermore, reviewed data suggest that in young preadolescent students (6-12 years), acute physical activity has a positive effect on attention, while chronic physical activity reveals a positive effect on executive functions, attention, and academic performance (de Greeff et al., 2018). In this context, Alesi et al. (2014) demonstrated that, as a result of regular Karate practice, 9-year-old Karate athletes exhibited better working memory and visual selective attention compared to their sedentary peers.

The impact of physical exercise on deficits of attention in children is a related subject and of relevance to the present study, because disturbances revealing a deficit of attention are displayed as one of the reasons of academic failure as much as they interfere with requirements of the school (Flessas and Lussier, 2001). Rates of Attention-Deficit/Hyperactivity Disorder (ADHD) in preschool children are rising constantly and ADHD prevalence is estimated to be at 2.1\% among U.S. American preschool children (Danielson et al., 2018). ADHD is a neurodevelopmental disorder characterized by symptoms of inattention and hyperactivity/impulsivity, which potentially causes lifetime impairment for afflicted individuals (American Psychiatric Association [APA], 2013). Since attention is a cognitive function and strongly implicated in the processes of learning (Flessas and Lussier, 2001) for both simple and complex activities (Flessas and Lussier, 2001; Delvolvé, 2005), we intended to analyze how a sensory-motor training in children influences behavior of inattention and hyperactivity and cognitive performance.
In this context, numerous studies demonstrated the significant effects of a sensory-motor training in children in terms of (i) decreased hyperactivity, anxiety, depression, and aggression (Banaschewski et al., 2001; Rosen et al., 2015) and (ii) reduction of behavioral and emotional problems (Sibley and Etnier, 2003; Haapala, 2012; Singh et al., 2012; Lees and Hopkins, 2013; MacCobb et al., 2014; Sandford et al., 2015). Consequently, physical activities and appropriate training programs are likely to boost cognitive functions (Hillman et al., 2014; Schmidt et al., 2015; Altenburg et al., 2016) and improve behavior and mood (Delvolvé, 2005; Gothe et al., 2013; MacCobb et al., 2014), whereby younger children seem to reveal higher benefits (Leconte, 2005).

Yoga is suggested to be an effective sensory-motor training for children to reduce behavioral and emotional problems and improve cognitive functions which might have a positive impact on academic performance (Chaya et al., 2012; Chou and Huang, 2017; Bazzano et al., 2018; Cohen et al., 2018). Recent studies demonstrated that yoga is one intervention with the potential to increase attention and academic performance in children (Chaya et al., 2012; Khalsa et al., 2012; Noggle et al., 2012; Chou and Huang, 2017) and adolescents (Khalsa et al., 2012; Noggle et al., 2012; Purohit and Pradhan, 2016). Yoga practice includes stretching postures, breathing exercises, and meditation (Taimini, 2005; Brethenoux-Seguin, 2007; Rosen et al., 2015). Indeed, conscious breathing has an impact on the parasympathetic system, causing a relaxation (Innes et al., 2005). Since yoga is a conscious exercise that builds attention control and inhibitory skills (Kaunhoven and Dorjee, 2017), it may have the potential to increase attention span on task during class and may represent an enjoyable and cost-effective treatment for children with and without attention problems (Peck et al., 2005).

Indeed, a growing body of evidence evolved underpinning the potential of yoga to support cognitive functioning in children and adolescents in different settings. Yoga was effective in improving delayed recall of spatial information and verbal memory in 11-16-year-old children (Manjunath and Telles, 2004). Similar results were reported for three months of yoga practice on executive functions of adolescent dwelling in an orphan home (Purohit and Pradhan, 2016). Yoga practice was an effective tool when working with students with Down syndrome, cerebral palsy, autism, sensory integration disorder, learning difficulties (Galantino et al., 2008), and attention deficit hyperactivity disorder (Balasubramaniam et al., 2012). In addition, yoga revealed a positive impact on cognitive functions in children with attention deficit and hyperactive disorder (American Psychiatric Association [APA], 2000; Harrison et al., 2004; Jensen and Kenny, 2004; Krisanaprakornkit et al., 2010; Diamond, 2012). Yoga is also associated with a positive effect on depression, anxiety, mod, self-esteem, and higher academic performance in children (Ortega et al., 2008). Additionally, yoga reduces negativity and aggression in children (Santangelo, 2012), improves social behavior in children aged 6-8 (Folleto et al., 2016), increases spatial memory scores, strategic planning, and concentration in children (Telles et al., 1993), as well as it improves cognitive performance of 7-9-year-old school children (Chaya et al., 2012). 
Nevertheless, research involving yoga and Kindergarten children is relatively sparse. Therefore, the main purpose of the present study is to analyze the impact of yoga practice in comparison to generic physical education (PE) and a passive control group (CG) on (i) attention as a cognitive performance (operationalized with the visual attention test) and visual-motor coordination (operationalized with the Visuomotor precision test) and (ii) ADHD relevant behavior of inattention and hyperactivity (operationalized with the ADHD Rating Scale-IV), in 5-year-old preschool Tunisian children.

We hypothesized that in comparison to the generic PE group as well as the passive CG, the yoga group would display a significant improvement in visual attention and visual-motor precision as well as a significant reduction in inattention and hyperactivity behavior.

\section{MATERIALS AND METHODS}

\section{Participants}

In this single-center, three-arm randomized, controlled study, 45 healthy children ( 28 female; 17 male; $5.2 \pm 0.4$ years) of a private Tunisian Kindergarten volunteered to participate. The Kindergarten is located in an urban setting and participants were from middle class families with a corresponding average to high socio-economic status. All participants and their legal guardians were informed in detail, in written form as well as orally, about the design of the study, including the potential risks and benefits. Subsequently, parents, respectively, legal guardians of the children, provided their informed written consent to participate. Participants were free to withdraw from the study at any time without further consequences. The inclusion criteria were a lack of any frequent participation in yoga exercise programs for at least 6 months prior to the study; no daily intake of medication; and for inclusion in the analysis, completion of at least $80 \%$ of the yoga sessions.

All procedures were conducted in accordance with the Code of Ethics for human experimentation of the World Medical Association, the Declaration of Helsinki (World Medical Association, 2013), as well as the ethical standards of the International Journal of Sports Medecine (Harriss and Atkinson, 2015). The experimental protocol was pre-approved by the ethical review board of the High Institute of Sport and Physical Education of University of Sfax, Tunisia.

\section{Overall Study Design}

Fifteen students performed a total of 24 yoga sessions, during a period of 12 weeks (two yoga sessions per week, $30 \mathrm{~min}$ per session) during regular Kindergarten hours, 15 students performed a generic PE program (24 sessions, two sessions per week, $30 \mathrm{~min}$ per session), and 15 students served as passive CG (Figure 1). Participants were randomly assigned to one of the three groups. Prior to $\left(T_{0}\right)$ and after the 12 weeks of either yoga, PE, or passive control $\left(T_{1}\right)$, all participants completed one subtest of the Developmental Neuropsychological Assessment (NEPSY) (Korkman et al., 1998) and one subtest of NEPSY-II (Korkman et al., 2007) and the teachers evaluated the inattention and hyperactivity behaviors of the participants with the help of the school version of the ADHD Rating Scale-IV (DuPaul et al., 1998). Since Kindergarten teachers evaluated the children's behavior with the help of the ADHD Rating Scale-IV, it was necessary to warrant impartiality of Kindergarten teachers toward the children. Therefore, Kindergarten teachers were not informed which children were assigned to the respective groups. Furthermore, teachers were not fully informed about the purpose of the study as well as about the nature and content of the two different interventions. The post-intervention testing started $72 \mathrm{~h}$ after the final scheduled session of yoga and PE (Figure 1).

\section{The Interventions}

The yoga group performed 24 yoga sessions (two yoga sessions per week, 30 min per session) involving Hatha yoga. An adapted Hatha yoga program was applied to meet the level of the children and the goals of the research. The yoga program was conducted by a certified yoga teacher. Each session during the 12 -week intervention involved a 30-min yoga program in the Kindergarten's gym. Each session included a 5 min preparatory period as a warm-up, comprising jogging and jumping followed by yoga specific stretching and loosening exercises and breathing exercises. During the main part of yoga sessions children performed yoga postures (Asana) for $15 \mathrm{~min}$ followed by $5 \mathrm{~min}$ of breathing techniques. The yoga postures included postures in standing, sitting, prone, and supine position. The breathing techniques (Pranayama) involved voluntary regulation of breathing like breathing with forceful exhalation and passive inhalation, breathing with rapid inhalation and exhalation, as well as slow and rhythmic alternate nostril breathing. At the end of each session yogic games for memory, awareness and creativity were completed (Figure 2). Throughout the different phases of the yoga session, a story was told to motivate the children for an active participation. The level of difficulty of yoga sessions increased from week to week to match the children's adaptations.

The PE group performed 24 regular PE sessions (two PE sessions per week, 30 min per session with moderate intensity) involving game-based activities, like basketball, soccer, handball, and relay games. The PE program was conducted by an instructor (trained undergraduate student) in the Kindergarten's gym.

In order to blind the interventions the following procedure was applied during the intervention period: Both yoga and PE were instructed and supervised by individuals not belonging to the Kindergarten's staff. The participating children were picked up in their respective groups by the investigators and escorted to the respective Gyms where yoga and PE were performed. The children were left in the custody of the yoga teacher, respectively, with the undergraduate student for the PE group. The children randomized to the passive CG were escorted by the investigators to other group rooms of the Kindergarten, which did not belong to the class of the children. In that group rooms, the children were free to play and engage in self-chosen activities like free play or artisanal activities. These group rooms were supervised by other Kindergarten teachers not belonging to the class of the child. All three activities (yoga, PE, and CG) were conducted parallel at the same time and in the absence of the teachers who rated the ADHD relevant behavior pretest and posttest. 


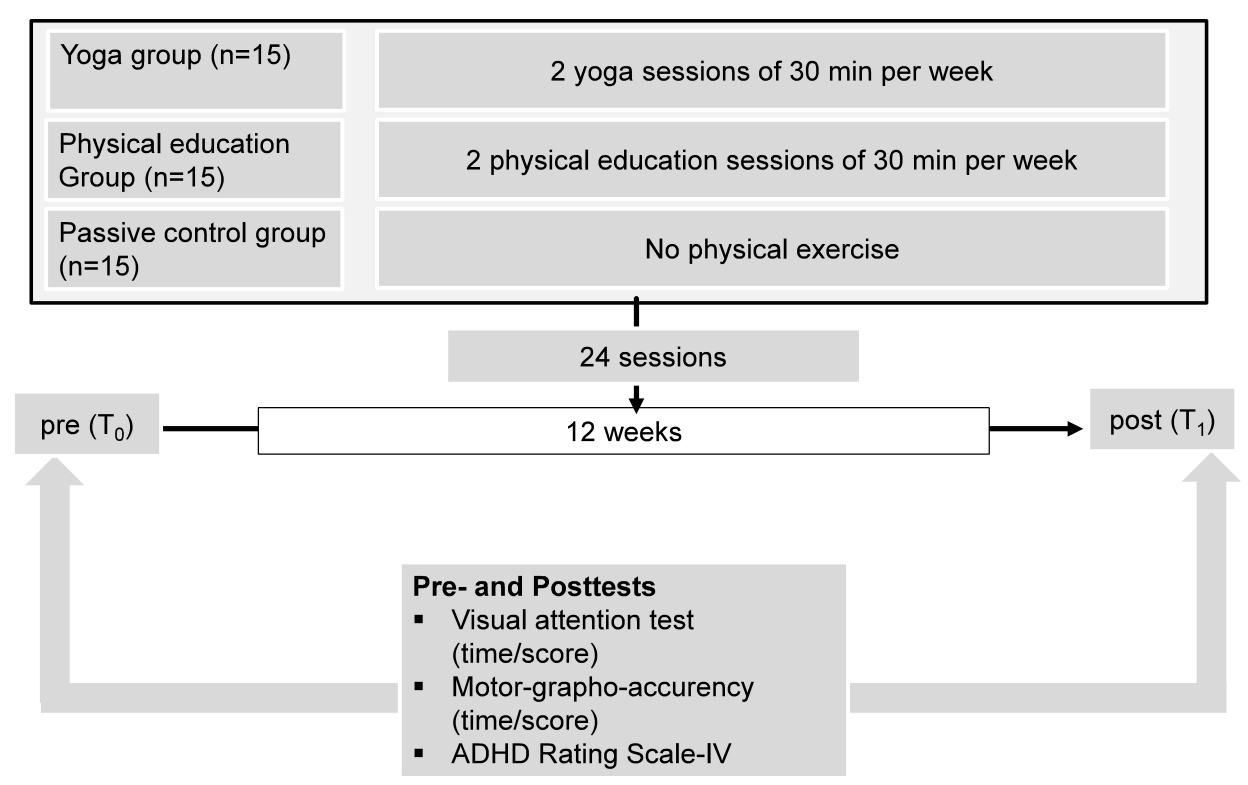

FIGURE 1 | Overview of the study protocols with pre- and post-tests.

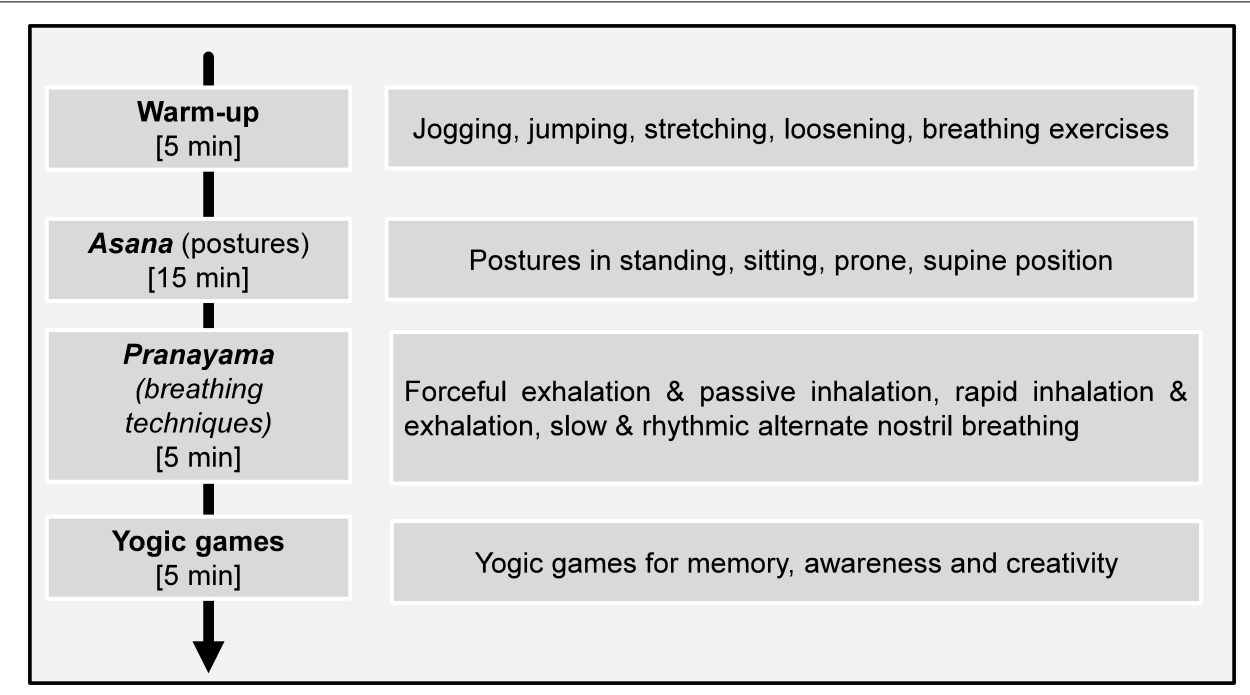

FIGURE 2 | Details of the yoga program.

Participants attended $91 \%$ of $\mathrm{PE}$ sessions and $88 \%$ of yoga sessions.

The CG completed no kind of physical exercise during the duration of the study.

\section{Visual Attention Test}

The visual attention test is one out of 27 subtest of the Developmental Neuropsychological Assessment (NEPSY) (Korkman et al., 1998). An instrument that provides a comprehensive neuropsychological assessment grouped into five domains (attention/executive function, language, memory and learning, sensorimotor functions, and visuospatial processing) for children aged 3-12 years (Korkman et al., 1998). Briefly, the Visual Attention subtest is allocated to the domain Attention and Executive Functioning and comprises a two-part visual cancellation task that assesses speed and precision at detecting targets among distractors.

\section{Visuomotor Precision Test}

The NEPSY-Second Edition (NEPSY-II) (Korkman et al., 2007) is an updated and modified version of the NEPSY (Korkman et al., 1998) and assessing neuropsychological functioning across the six domains attention and executive functioning, language, memory and learning, sensorimotor, social perception, and visuospatial 
processing with the help of several subtests. As part of the NEPSY-II, as described in detail elsewhere (Korkman et al., 2007), the subtest Visuomotor Precision is designed to assess neuropsychological functioning in the domain of sensorimotor function. The subtest measured the time in which participants perform a visuomotor task as well as the precision of the graphics performed in this task. The children using the preferred hand to draw lines inside of tracks as quickly and precise as possible.

\section{ADHD Rating Scale-IV}

The ADHD Rating Scale-IV (DuPaul et al., 1998) is a normreferenced checklist that measures the symptoms of ADHD based on the diagnostic criteria of the Diagnostic and Statistical Manual of Mental Disorders (American Psychiatric Association [APA], 2000). As described in detail elsewhere (DuPaul et al., 1998), the ADHD Rating Scale-IV (French version) measures the frequency of two distinct behaviors: (1) symptoms associated with inattention and (2) symptoms associated with hyperactivity/impulsivity. In the present study, the inattention and hyperactivity behaviors of the participants were evaluated by the Kindergarten teacher with the help of the school version of the ADHD Rating Scale-IV (DuPaul et al., 1998). Whereas, the same preschool teacher evaluated the child at $\left(T_{0}\right)$ and $\left(T_{1}\right)$. The teacher assesses symptom frequency using a fourpoint Likert scale. The questionnaire consists of 18 items, nine items relating to inattention and nine items relating to hyperactivity. The behavioral scale of the students (DuPaul et al., 1998) is an instrument for assessing frequency of inattention and hyperactivity/impulsivity behaviors. Results are described in terms of the Inattention subscale and the Hyperactivityimpulsivity subscale as well as the total score.

\section{Empirical Hypothesis}

Yoga has a significant positive impact on the development of visual attention, visuomotor precision, and ADHD behavior in comparison to generic $\mathrm{PE}$ as well as in comparison to CG.

\section{Statistical Analysis}

Statistical tests were processed using SPSS software for Windows, version 25 (IBM, Armonk, NY, United States). Mean and standard deviation (SD) values were calculated for each variable. G* power software (Faul et al., 2007) was applied to calculate the required sample size. Values for $\alpha$ were set at 0.05 and power at 0.80 . Based on discussions between the authors, effect size was estimated to be 0.7 (medium effect). Required sample size was 55 participants. Due to practical reasons like availability, 45 children could be included.

The Shapiro-Wilk test revealed that data of $T_{0}$ and $T_{1}$ was normally distributed and homogeneity of variance (Levene test) was given with no transformation necessary. A repeated measures analysis of variance was performed to analyze the impact of yoga in comparison to generic PE (2 [group] $\times 2$ [time-of-measure]) as well as in comparison to CG (2 [group] $\times 2$ [time-ofmeasure]). In addition to repeated measures analysis of variance, Bonferroni-Holm corrections were performed. Furthermore, data of $T_{0}$ were checked for significant differences between the three groups, applying a one-way ANOVA. A probability level of 0.05 was selected a priori as the criterion for statistical significance. To estimate practical relevance, effect sizes (partial eta squared, $\eta p^{2}$ ) (Richardson, 2011) were calculated with $\eta \mathrm{p}^{2} \geq 0.01$ indicated small, $\geq 0.06$ medium, and $\geq 0.14$ large effects (Clark-Carter, 1997).

\section{RESULTS}

All parameters measured at $T_{0}$ and $T_{1}$ with accompanying statistical analyses are presented in Table 1. All parameters measured at $T_{0}$ did not show significant differences between the three groups $(p>0.001)$.

\section{Visual Attention}

Yoga has a non-significant impact on the development of visual attention $\mathrm{A}$ in comparison to generic $\mathrm{PE}$ [time $\times$ group effect: $\left.F(1,28)=2.62 ; p=0.117 ; \eta p^{2}=0.086\right]$. However, yoga has a significant positive impact on the development of visual attention $\mathrm{A}$ in comparison to $\mathrm{CG}$ [time $\times$ group effect: $F(1,28)=5.23$; $\left.p=0.030 ; \eta p^{2}=0.157\right] ;$ yoga $\left(T_{0}: 1.41 \pm 0.07, T_{1}: 1.31 \pm 0.05\right)$ leads to comparatively faster attention times (CG: $T_{0}: 1.41 \pm 0.06$, $\left.T_{1}: 1.39 \pm 0.07\right)$. In addition, yoga has a significant positive impact on the development of visual attention $B$ in comparison to PE [time $\times$ group effect: $F(1,28)=5.49 ; p=0.026 ; \eta p^{2}=0.164$ ] as well as in comparison to CG [time $\times$ group effect: $F(1,28)=11.45$; $\left.p=0.002 ; \eta p^{2}=0.290\right]$; in both cases, yoga $\left(T_{0}: 8.87 \pm 1.64\right.$, $T_{1}: 12.20 \pm 1.61$ ) leads to comparatively higher scores (PE: $T_{0}: 8.93 \pm 1.03, T_{1}: 10.53 \pm 1.30 ;$ CG: $T_{0}: 9.33 \pm 1.80$, $\left.T_{1}: 10.13 \pm 1.68\right)$. All significant interaction effects can be classified as large.

However, after Bonferroni-Holm correction, only one significant time $\times$ group interaction effect remained. Hereafter, yoga has a significant positive impact on the development of visual attention B in comparison to CG (adj. $p=0.005)$.

\section{Visuomotor Precision}

Yoga has a significant positive impact on the development of visuomotor precision $\mathrm{A}$ in comparison to generic $\mathrm{PE}$ [time $\times$ group effect: $F(1,28)=19.62 ; p=0.000 ; \eta p^{2}=0.412$ ] as well as in comparison to CG [time $\times$ group effect: $F(1,28)=4.92$; $\left.p=0.035 ; \eta p^{2}=0.149\right]$; in both cases, yoga $\left(T_{0}: 24.58 \pm 1.25\right.$, $\left.T_{1}: 21.06 \pm 1.47\right)$ leads to comparatively faster visuomotor precision times (PE: $24.25 \pm 1.17, T_{1}: 23.69 \pm 1.86$; CG: $\left.T_{0}: 26.17 \pm 2.09, T_{1}: 24.64 \pm 3.21\right)$. Further, yoga has a significant positive impact on the development of visuomotor precision $\mathrm{A}$ in comparison to generic $\mathrm{PE}$ [time $\times$ group effect: $\left.F(1,28)=4.82 ; p=0.037 ; \eta p^{2}=0.147\right]$; yoga $\left(T_{0}: 11.33 \pm 1.45\right.$, $\left.T_{1}: 8.93 \pm 1.75\right)$ leads to comparatively lower error rates (PE: $T_{0}: 11.73 \pm 1.91, T_{1}: 11.07 \pm 1.22$ ). However, yoga has no significant impact on the development of visual attention $\mathrm{A}$ in comparison to CG [time $\times$ group effect: $F(1,28)=2.74 ; p=0.109$; $\left.\eta \mathrm{p}^{2}=0.089\right]$. In addition, yoga has a significant positive impact on the development of visuomotor precision $\mathrm{B}$ in comparison to generic PE [time $\times$ group effect: $F(1,28)=34.96 ; p=0.000$; $\eta \mathrm{p}^{2}=0.555$ ] as well as in comparison to CG [time $\times$ group effect: $\left.F(1,28)=7.64 ; p=0.010 ; \eta p^{2}=0.214\right]$; in both cases, yoga 


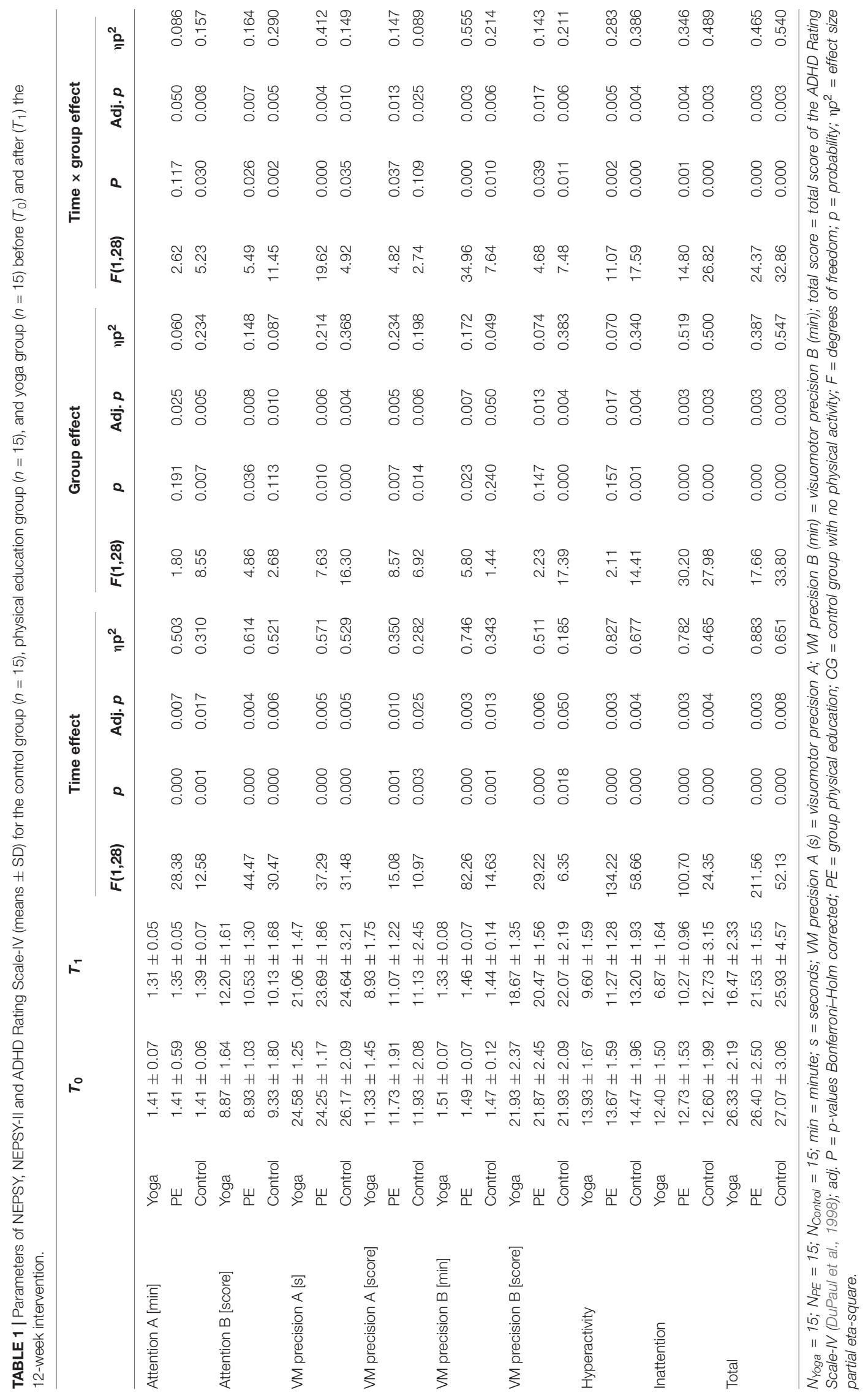


$\left(T_{0}: 1.51 \pm 0.07, T_{1}: 1.33 \pm 0.08\right)$ leads to comparatively faster visuomotor precision times (PE: $T_{0}: 1.49 \pm 0.07, T_{1}: 1.46 \pm 0.07$; CG: $\left.T_{0}: 1.47 \pm 0.12, T_{1}: 1.44 \pm 0.14\right)$. Finally, yoga has a significant positive impact on the development of visuomotor precision $\mathrm{B}$ in comparison to generic $\mathrm{PE}$ [time $\times$ group effect: $\left.F(1,28)=4.68 ; p=0.039 ; \eta p^{2}=0.143\right]$ as well as in comparison to non-treatment conditions [time $\times$ group effect: $F(1,28)=7.48$; $\left.p=0.011 ; \eta p^{2}=0.211\right]$; in both cases, yoga $\left(T_{0}: 21.93 \pm 2.37\right.$, $\left.T_{1}: 18.67 \pm 1.35\right)$ leads to comparatively lower error rates (PE: $T_{0}: 21.87 \pm 2.45, T_{1}: 20.47 \pm 1.56$; CG: $T_{0}: 21.93 \pm 2.09$, $\left.T_{1}: 22.07 \pm 2.19\right)$. All significant interaction effects can be classified as large.

However, after Bonferroni-Holm correction, only two significant time $\times$ group interaction effects remained. Hereafter, yoga has a significant positive impact on both, the development of visuomotor precision A (completion time) in comparison to PE (adj. $p=0.004$ ) as well as visuomotor precision B (completion time) in comparison to PE group (adj. $p=0.003$ ).

\section{ADHD Rating Scale-IV}

Yoga has a significant positive impact on the development of hyperactivity behavior in comparison to generic $\mathrm{PE}$ [time $\times$ group effect: $F(1,28)=11.07 ; p=0.002 ; \eta p^{2}=0.283$ ] as well as in comparison to CG [time $\times$ group effect: $F(1,28)=17.59$; $\left.p=0.000 ; \eta p^{2}=0.386\right]$; in both cases, yoga $\left(T_{0}: 13.93 \pm 1.67, T_{1}\right.$ : $9.60 \pm 1.59)$ leads to comparatively lower hyperactivity behavior $\left(\mathrm{PE}: 13.67 \pm 1.59, T_{1}: 11.27 \pm 1.28\right.$; CG: $T_{0}: 14.47 \pm 1.96, T_{1}$ : $13.20 \pm 1.93)$. Further, yoga has a significant positive impact on the development of inattention behavior in comparison to generic PE [time $\times$ group effect: $F(1,28)=14.80 ; p=0.001$; $\eta p^{2}=0.346$ ] as well as in comparison to CG [time $\times$ group effect: $F(1,28)=26.82 ; p=0.000 ; \eta p^{2}=0.489$ ]; in both cases, yoga $\left(T_{0}: 12.40 \pm 1.50, T_{1}: 6.87 \pm 1.64\right)$ leads to comparatively lower inattention scores (PE: $12.73 \pm 1.53, T_{1}: 10.27 \pm 0.96$; CG: $\left.T_{0}: 12.60 \pm 1.99, T_{1}: 12.73 \pm 3.15\right)$. Finally, yoga has a significant positive impact on the ADHD total score in comparison to generic PE [time $\times$ group effect: $F(1,28)=24.37 ; p=0.000$; $\eta \mathrm{p}^{2}=0.465$ ] as well as in comparison to CG [time $\times$ group effect: $\left.F(1,28)=32.86 ; p=0.000 ; \eta p^{2}=0.540\right]$; in both cases, yoga $\left(T_{0}\right.$ : $\left.26.33 \pm 2.19, T_{1}: 16.47 \pm 2.33\right)$ leads to comparatively lower ADHD-total-scores (PE: $26.40 \pm 2.50, T_{1}: 21.53 \pm 1.55$; CG: $\left.T_{0}: 27.07 \pm 3.06, T_{1}: 25.93 \pm 4.57\right)$. All significant interaction effects can be classified as large. Following Bonferroni-Holm corrections, all reported time $\times$ group interaction effects remained significant (Table 1).

\section{DISCUSSION}

The aim of this study was to investigate the effects of 12 -week Kindergarten-based yoga practice on visual attention, visualmotor precision, as well as on hyperactivity and inattention behavior in 5-year-old Tunisian children.

The main findings of the present study were as follows:

(1) Yoga had a significant positive effect over the 12-week intervention period on the majority of parameters of visual attention and on parameters of visual-motor precision, in comparison to the PE and CG. However, after Bonferroni-Holm correction, yoga only had a significant positive impact on the development of visual attention B in comparison to CG. Considering visual-motor precision after Bonferroni-Holm correction, yoga only had a significant positive impact on the development of visuomotor precision A (completion time) in comparison to $\mathrm{PE}$, as well as on visuomotor precision $\mathrm{B}$ (completion time) in comparison to PE group.

(2) Hyperactivity and inattention behavior and the total score of the ADHD Rating Scale-IV improved significantly in the yoga group from $T_{0}$ to $T_{1}$, in comparison to the PE and CG.

The results demonstrate that children participating in the yoga program, in comparison to the PE and CG, improved their skills related to cognitive functions, measured by the subtests of NEPSY (Korkman et al., 1998) and NEPSY-II (Korkman et al., 2007), as well as their behavior in respect to inattention and hyperactivity, evaluated by the ADHD Rating Scale-IV (DuPaul et al., 1998). The amelioration of attention with the help of yoga in the present study is in line with previous results demonstrating that sensorimotor training enhances attention in children with (Banaschewski et al., 2001; Cohen et al., 2018) and without ADHD (Mak et al., 2018). Our results are also coherent with previous studies reporting that schoolbased prevention programs focusing on yoga or sensorimotor training for young children can reduce deficits in attention and improve academic performance (Paour and Cèbes, 2001; Chevalier and Simard, 2006; Krisanaprakornkit et al., 2010; Gothe et al., 2013). In addition, our results support findings of previous research demonstrating that yoga practice decreases ADHD symptoms in preschool children (Cohen et al., 2018). Although, no manifest ADHD diagnosis (e.g., from a clinician, psychologist, or pediatrician) was evident for participants of the present study, many participants showed symptoms of inattention, hyperactivity, and impulsivity at $T_{0}$ (Table 1). With the yoga intervention, the inattention behavior in the present study was reduced effectively.

Since attention represents an important prerequisite in the processes of learning (Flessas and Lussier, 2001; McClelland et al., 2013) and is associated with better academic performance in preschool children (Duncan et al., 2007) as well as executive functions (Friedman et al., 2007) and academic performance (McClelland et al., 2013) in the adolescence, the present study demonstrated that yoga has the potential to facilitate learning processes and may contribute to academic achievement of preadolescent children. Furthermore, it seems to be important to work on attention problems at an early age, because attention problems during childhood seem to be associated with poorer executive functions in late adolescence (Friedman et al., 2007). Recent reviews calculated a positive small to moderate effect on attention for acute physical activity and a large positive effect on attention for chronic physical activity (de Greeff et al., 2018). In agreement with the recent review (de Greeff et al., 2018), the present study revealed large positive effect sizes for the chronic yoga intervention on attention. It is suggested that 
the positive effects on attention leading to increased time children are engaged in academic tasks, which has the potential of better academic performance in the long run (Duncan et al., 2007; Oberer et al., 2018). It is hypothesized that both increased physical activity, respectively, an increased physical fitness as a result of the latter leading to an increased activity in selective structures of the brain, causing functional and structural connectivity (Esteban-Cornejo et al., 2017). As a result, physical activity potentially facilitates factors of cognitive performance and executive functions (Diamond, 2000; Colcombe and Kramer, 2003). For the exact underlying mechanisms of structural and functional brain changes associated with physical exercise in children, the available research is very limited in number and scope. Whereas, associations of cardiorespiratory fitness and speed-agility in obese children (8-11 years) with greater gray matter volumes, which in turn reflect children's academic performance, could be demonstrated recently (Esteban-Cornejo et al., 2017). Additionally, an 8-month aerobic exercise program with 8-11-year-old obese children caused improved white matter integrity in the brain tract connecting frontal and temporal lobes (Schaeffer et al., 2014). In addition, an improved memory performance in children was associated with improved frontotemporal circuitry as a result of aerobic exercise (Erickson et al., 2011). To the best of our knowledge, no studies are available on yoga and the effects of structural alterations of brain matter in children. Whereas, reviewed data suggest several structural alterations and activation changes of brain structures (e.g., amygdala, frontal lobes, white matter) in adults as a result of yoga (for detailed description of specific changes, see Desai et al., 2015). Similar alterations in structural and functional capacities in the brain of children may be responsible for the alterations of attention and behavior in the present study.

The present results imply that improvements in cognitive tasks were achieved after a yoga intervention compared to generic PE and the usual Kindergarten activities as represented in the CG. These results are in agreement with previous studies, which reported that young yoga participants showed significant differences over time on measures of executive functions (Manjunath and Telles, 2004; Chaya et al., 2012; Purohit and Pradhan, 2016). Likewise, Telles et al. (1993) revealed that children, practicing yoga for 10 days, improved in spatial memory scores, strategic planning, and concentration. In the same context, a significant improvement following 12 weeks of schoolbased yoga was observed for cognitive functions and memory in 13-year-old children (Verma et al., 2014). In agreement with studies on yoga with older children, our data demonstrate that preschool-based yoga is a suitable physical exercise to support cognitive abilities of preschool children. Since the level of physical activity, executive functions, and visual-motor coordination in Kindergarten children seem to be associated with later academic achievement (Oberer et al., 2018), it seems to be beneficial to implement regular yoga classes at preschools to contribute to the basis for academic achievement in young children. In this context, several authors advocate the potential of yoga for schools as an enjoyable and cost-effective exercise to improve cognitive and behavioral skills, which are relevant for school and may contribute to academic achievement (Kauts and Sharma, 2009;
Chaya et al., 2012; Verma et al., 2014). The observation of the practical application of yoga at schools worldwide reveals that yoga is increasingly important in the school setting (Flak, 2003; Chaya et al., 2012) since it is recognized in the curriculum in France, Brazil, Canada, and Italy (Flak, 2003). Additionally, in Italy, classroom-based yoga is performed in all schools since 2000 (Flak, 2003).

Although no explicit ADHD patients were among participants of the present study, the yoga intervention reduced the behavior of hyperactivity and inattention significantly and to a practical relevant extent, which is in line with numerous studies. Previous research demonstrated that a sensorimotor training program for children leads to the reduction of behavioral problems (Eggert and Lütje, 1991) and ameliorates anger control and anxiety (Khalsa et al., 2012), factors that potentially interfere with academic achievement and psychosocial wellbeing. Furthermore, classroom-based yoga leads to a significant improvement in emotional and psychosocial quality of life and reduced anxiety in third-grade students (Bazzano et al., 2018). Additionally, Noggle et al. (2012) reported that school-based yoga in high school students caused increases in measures of psychosocial well-being in comparison with the regular PE. Consequently, yoga could be considered as a method to teach coping skills for young students which potentially contribute to mental health and psychosocial well-being.

As noted by Rossner (1995), yoga would allow relaxation to improve attention to task and spatial relationships in the environment, which we confirmed by our results. The findings of the present study provide evidence for the importance of practicing yoga at Kindergarten as it helps reach higher cognitive performance and consequently potentially higher academics performances in children. Thus, yoga seems to be an appropriate tool to a cognitive education to preschool Tunisian children as a complement to the usual social, emotional, and artisanal learning activities. As recommended (Paour and Cèbes, 2001), yoga would allow the preschool children to effectively engage attentional abilities and improve the executive self-regulation of the action.

\section{Limitations}

Whereas, it would be useful to have a larger sample since our study consisted of 45 participants and this may present a limitation since the variability may be significant in this sample. Furthermore, a greater number of participants would have given more statistical power to the data interpretation with less risk of calculating type 2 errors. At the same time, the small sample size allowed us to increase availability, motivation, and compliance of children during participation.

The duration of a yoga session is usually approximately $1: 20 \mathrm{~h}$ (Lark, 2003) and the $30 \mathrm{~min}$ of yoga allotted to each class in the present study could represent a limitation. We reduced the sessions to $30 \mathrm{~min}$ in order to respect the attention span of the children as well as the schedule allocated for the daily routines of the Kindergarten. Nevertheless, the duration of $30 \mathrm{~min}$ of yoga sessions in the present study is within the usual range of 30-40 min of comparable studies (Chou and Huang, 2017; Bazzano et al., 2018). 
The inattention and hyperactivity behaviors of the participants were evaluated by the Kindergarten teacher with the help of the ADHD Rating Scale-IV (DuPaul et al., 1998). The Kindergarten teachers were not informed about the hypothesis of the study and blinded to the intervention groups and the passive CG. We only informed Kindergarten teachers that different kinds of physical exercise were tested on cognitive functions in the children. Whereas, we cannot exclude that children told their Kindergarten teachers about the performed intervention or that Kindergarten teachers eventually had intuitions concerning expected results of the yoga intervention.

The present study is part of a research project focusing on graphic design and its link with motor and cognitive aspects. We consider fine motor skills as especially important during preschool age since writing is a fine motor activity that is initiated during the preschool period and requires perceptual-motor skills. In children aged between 2-4 years, the vision serves as a primary guide for graphic activities like writing (James, 2010; Maldarelli et al., 2015). Therefore, we did not include auditory attention tests. Since auditory stimuli are an additional prerequisite for graphic activities, we are looking forward to implement auditory attention tests in the following parts of the research project.

\section{CONCLUSION}

Twelve weeks of two 30-min yoga sessions per week improved certain parameters of attention, visual-motor precision, and reduced behavior of inattention and hyperactivity in 5-year-old Kindergarten children. The yoga program improves attention, visual-motor precision, and behavior to a higher extent compared to generic $\mathrm{PE}$ and the usual Kindergarten activities as represented in the passive CG. As a consequence, Kindergarten-based yoga classes represents a sufficient and cost-benefit effective exercise activity which may enhance functions relevant for learning among young children and could be added as a complement to social, emotional, and artisanal learning activities at the Kindergarten.

\section{ETHICS STATEMENT}

In this single-center, three-arm randomized, controlled study, 45 healthy children (28 female; 17 male; $5.2 \pm 0.4$ years) of

\section{REFERENCES}

Alesi, M., Bianco, A., Padulo, J., Vella, F. P., Petrucci, M., Paoli, A., et al. (2014). Motor and cognitive development: the role of karate. Muscle Ligaments Tendons J. 14, 114-120. doi: 10.11138/mltj/2014.4.2.114

Altenburg, T. M., Chinapaw, M. J., and Singh, A. S. (2016). Effects of one versus two bouts of moderate intensity physical activity on selective attention during a school morning in Dutch primary schoolchildren: a randomized controlled trial. J. Sci. Med. Sport. 19, 820-824. doi: 10.1016/j.jsams.2015. 12.003

American Psychiatric Association [APA] (2000). DSM-IV-TR: Diagnostic and Statistical Manual of Mental Disorders. Washington, DC: American Psychiatric Association. a private Tunisian Kindergarten volunteered to participate. All participants and their legal guardians were informed in detail, in written form as well as orally, about the design of the study, including the potential risks and benefits, before providing their informed written consent to participate. Participants were free to withdraw from the study at any time without further consequences. The inclusion criteria were a lack of any frequent participation in yoga exercise programs for at least 6 months prior to the study; no daily intake of medication; and for inclusion in the analysis, completion of at least $80 \%$ of the yoga sessions.

All procedures were conducted in accordance with the Code of Ethics for human experimentation of the World Medical Association, the Declaration of Helsinki (World Medical Association, 2013), as well as the ethical standards of the International Journal of Sports Medecine (Harriss and Atkinson, 2015). The experimental protocol was pre-approved by the ethical review board of the High Institute of Sport and Physical Education of University of Sfax, Tunisia.

\section{AUTHOR CONTRIBUTIONS}

All authors have made a substantial, direct, and intellectual contribution to the work and approved it for publication.

\section{FUNDING}

This study was financially supported by the Ministry of Higher Education and Scientific Research, Tunisia. We acknowledge financial support by Deutsche Forschungsgemeinschaft within the funding programme Open Access Publishing, by the BadenWürttemberg Ministry of Science, Research, and the Arts, and by Ruprecht-Karls-Universität Heidelberg.

\section{ACKNOWLEDGMENTS}

The authors wish to express their sincere gratitude to all the participants for their maximal effort and cooperation.

American Psychiatric Association [APA] (2013). Diagnostic and Statistical Manual of Mental Disorders, 5th Edn. Washington, DC: American Psychiatric Association. doi: 10.1176/appi.books.9780890425596

Balasubramaniam, M., Telles, S., and Doraiswamy, P. M. (2012). Yoga on our minds: a systematic review of yoga for neuropsychiatric disorders. Front. Psychiatry 25:117. doi: 10.3389/fpsyt.2012.00117

Banaschewski, T., Besmens, F., Zieger, H., and Rothenberger, A. (2001). Evaluation of sensorimotor training in children with ADHD. Percept. Mot. Skills 92, 137-149. doi: 10.2466/pms.2001.92.1.137

Bazzano, A. N., Anderson, C. E., Hylton, C., and Gustat, J. (2018). Effect of mindfulness and yoga on quality of life for elementary school students and teachers: results of a randomized controlled school-based study. Psychol. Res. Behav. Manag. 11, 81-89. doi: 10.2147/PRBM.S157503 
Blair, C., and Raver, C. C. (2015). School readiness and self-regulation: a developmental psychobiological approach. Annu. Rev. Psychol. 66, 711-731. doi: 10.1146/annurev-psych-010814-015221

Brethenoux-Seguin, F. (2007). Yoga \& Bonne Santé. Paris: Edition ESTEM De Boeck.

Chaya, M. S., Nagendra, H., Selvam, S., Kurpad, A., and Srinivasan, K. (2012). Effect of yoga on cognitive abilities in schoolchildren from a socioeconomically disadvantaged background: a randomized controlled study. J. Altern. Complement. Med. 18, 1161-1167. doi: 10.1089/acm. 2011.0579

Chevalier, N., and Simard, F. (2006). "Programmes sensorimoteurs pour jeunes ayant un TDAH et des troubles associés," in Trouble Déficitaire De L'attention Avec Hyperactivité: Soigner, Éduquer, Surtout Valoriser, ed. S. Foy (Québec: Presses de l'Université du Québec), 141-158.

Chou, C. C., and Huang, C. J. (2017). Effects of an 8-week yoga program on sustained attention and discrimination function in children with attention deficit hyperactivity disorder. PeerJ. 5:e2883. doi: 10.7717/peerj.2883

Clark-Carter, D. (1997). Doing Quantitative Psychological Research: From Design to Report. Hove: Psychology Press.

Cohen, S. C. L., Harvey, D. J., Shields, R. H., Shields, G. S., Rashedi, R. N., Tancredi, D. J., et al. (2018). Effects of yoga on attention, impulsivity, and hyperactivity in preschool-aged children with attention-deficit hyperactivity disorder symptoms. J. Dev. Behav. Pediatr. 39, 200-209. doi: 10.1097/DBP. 0000000000000552

Colcombe, S. J., and Kramer, A. F. (2003). Fitness effects on the cognitive function of older adults: a meta-analytic study. Psychol. Sci. 14, 125-130. doi: 10.1111/ 1467-9280.t01-1-01430

Danielson, M. L., Bitsko, R. H., Ghandour, R. M., Holbrook, J. R., Kogan, M. D., and Blumberg, S. J. (2018). Prevalence of parent-reported ADHD diagnosis and associated treatment among U.S. children and adolescents, 2016. J. Clin. Child. Adolesc. Psychol. 47, 199-212. doi: 10.1080/15374416.2017.1417860

de Greeff, J. W., Bosker, R. J., Oosterlaan, J., Visscher, C., and Hartman, E. (2018). Effects of physical activity on executive functions, attention and academic performance in preadolescent children: a meta-analysis. J. Sci. Med. Sport 21, 501-507. doi: 10.1016/j.jsams.2017.09.595

Delvolvé, N. (2005). Tous Les Élèves Peuvent Apprendre. Approches Psychologiques Et Ergonomiques Des Apprentissages Scolaires. Paris: Ed. Hachette Education.

Desai, R., Tailor, A., and Bhatt, T. (2015). Effects of yoga on brain waves and structural activation: a review. Complement. Ther. Clin. Pract. 21, 112-118. doi: 10.1016/j.ctcp.2015.02.002

Diamond, A. (2000). Close interrelation of motor development and cognitive development and of the cerebellum and prefrontal cortex. Child Dev. 71, 44-56. doi: $10.1111 / 1467-8624.00117$

Diamond, A. (2012). Activities and programs that improve children's executive functions. Curr. Dir. Psychol. Sci. 21, 335-341. doi: 10.1177/09637214124 53722

Diamond, A. (2013). Executive functions. Annu. Rev. Psychol. 64, 135-168. doi: 10.1146/annurev-psych-113011-143750

Duncan, G. J., Dowsett, C. J., Claessens, A., Magnuson, K., Huston, A. C., Klebanov, P., et al. (2007). School readiness and later achievement. Dev. Psychol. 43, 1428-1446. doi: 10.1037/0012-1649.43.6.1428

DuPaul, G. J., Power, T. J., Anastopoulos, A. D., and Reid, R. (1998). ADHD Rating Scale-IV: Checklists, Norms and Clinical Interpretation. New York, NY: Guilford.

Eggert, D., and Lütje, B. (1991). Psychomotorik in der (Sonder-)Schule. Empirische studien zu den grenzen eines förderkonzepts. Praxis Der Psychomotorik 3, $156-168$.

Erickson, K. I., Voss, M. W., Prakash, R. S., Basak, C., Szabo, A., Chaddock, L., et al. (2011). Exercise training increases size of hippocampus and improves memory. Proc. Natl. Acad. Sci. U.S.A. 108, 3017-3022. doi: 10.1073/pnas.1015950108

Esteban-Cornejo, I., Cadenas-Sanchez, C., Contreras-Rodriguez, O., VerdejoRoman, J., Mora-Gonzalez, J., Migueles, J. H., et al. (2017). A whole brain volumetric approach in overweight/obese children: examining the association with different physical fitness components and academic performance. The active brains project. Neuroimage 159, 346-354. doi: 10.1016/j.neuroimage. 2017.08.011

Faul, F., Erdfelder, E., Lang, A. G., and Buchner, A. G. (2007). G*Power 3: a flexible statistical power analysis program for the social, behavioral, and biomedical sciences. Behav. Res. Methods 2007, 175-191. doi: 10.3758/BF03193146
Fedewa, A. L., and Ahn, S. (2011). The effects of physical activity and physical fitness on children's achievement and cognitive outcomes: a meta-analysis. Res. Q. Exerc. Sport 82, 521-535. doi: 10.1080/02701367.2011.10599785

Flak, M. (2003). Recherche Sur Le Yoga Dans Léducation. 3ème Millénaire: Spiritualité - Connaissance De Soi - Non-Dualité - Méditation, 125. Available at: http://www.rye-yoga.fr/ (accessed July 15, 2018).

Flessas, L., and Lussier, F. (2001). Neuropsychologie De L'enfant. Troubles Développementaux Et De L'apprentissage. Paris: Dunod.

Folleto, J. C., Pereira, K. R., and Valentini, N. C. (2016). The effects of yoga practice in school physical education on children's motor abilities and social behavior. Int. J. Yoga 9, 156-162. doi: 10.4103/0973-6131.183717

Friedman, N. P., Haberstick, B. C., Willcutt, E. G., Miyake, A., Young, S. E., Corley, R. P., et al. (2007). Greater attention problems during childhood predict poorer executive functioning in late adolescence. Psychol. Sci. 18, 893-900. doi: 10.1111/j.1467-9280.2007.01997.x

Galantino, M. L., Galbavy, R., and Quinn, L. (2008). Therapeutic effects of yoga for children: a systematic review of the literature. Pediatr. Phys. Ther. 20, 66-80. doi: 10.1097/PEP.0b013e31815f1208

Gothe, N., Pontifex, M. B., Hillman, C., and McAuley, E. (2013). The acute effects of yoga on executive function. J. Phys. Act. Health 10, 488-495. doi: 10.1123/ jpah.10.4.488

Haapala, E. (2012). Physical activity, academic performance and cognition in children and adolescents. A systematic review. Baltic J. Health Phys. Act. 4, 53-61. doi: 10.2478/v10131-012-0007-y

Harrison, L. J., Manocha, R., and Rubia, K. (2004). Sahaja yoga meditation as a family treatment programme for children with attention deficithyperactivity disorder. Clin. Child Psychol. Psychiatry 9, 479-497. doi: 10.1177/ 1359104504046155

Harriss, D. J., and Atkinson, G. (2015). Ethical standards in sport and exercise science research: 2016 update. Int. J. Sports Med. 36, 1121-1124. doi: 10.1055/s0035- 1565186

Hillman, C. H., Pontifex, M. B., Castelli, D. M., Khan, N. A., Raine, L. B., Scudder, M. R., et al. (2014). Effects of the FITKids randomized controlled trial on executive control and brain function. Pediatrics 134, e1063-e1071. doi: 10.1542/ peds.2013-3219

Innes, K. E., Bourguignon, C., and Taylor, A. G. (2005). Risk indices associated with the insulin resistance syndrome, cardiovascular disease, and possible protection with yoga: a systematic review. J. Am. Board Fam. Pract. 18, 491-519. doi: 10.3122/jabfm.18.6.491

James, K. H. (2010). Sensori-motor experience leads to changes in visual processing in the developing brain. Dev. Sci. 13, 279-288. doi: 10.1111/j.1467-7687.2009. 00883.x

Jensen, P. S., and Kenny, D. T. (2004). The effects of yoga on the attention and behavior of boys with Attention-Deficit/hyperactivity Disorder (ADHD). J. Atten. Disord. 7, 205-216. doi: 10.1177/108705470400700403

Kaunhoven, R. J., and Dorjee, D. (2017). How does mindfulness modulate self-regulation in pre-adolescent children? An integrative neurocognitive review. Neurosci. Biobehav. Rev. 74, 163-184. doi: 10.1016/j.neubiorev.2017. 01.007

Kauts, A., and Sharma, N. (2009). Effect of yoga on academic performance in relation to stress. Int. J. Yoga 2, 39-43. doi: 10.4103/0973-6131.53860

Khalsa, S. B., Hickey-Schultz, L., Cohen, D., Steiner, N., and Cope, S. (2012). Evaluation of the mental health benefits of yoga in a secondary school: a preliminary randomized controlled trial. J. Behav. Health Serv. Res. 39, 80-90. doi: 10.1007/s11414-011-9249-8

Korkman, M., Kirk, U., and Kemp, S. (1998). NEPSY: A Developmental Neuropsychological Assessment Manual. San Antonio, TX: The Psychological Corporation.

Korkman, M., Kirk, U., and Kemp, S. (2007). NEPSY-Second Edition (NEPSY-II). San Antonio, TX: Harcourt Assessment.

Krisanaprakornkit, T., Ngamjarus, C., Witoonchart, C., and Piyavhatkul, N. (2010). Meditation therapies for attention-deficit/hyperactivity disorder (ADHD). Cochrane Database Syst. Rev. 6:CD006507. doi: 10.1002/14651858.CD006507. pub2

Lark, L. (2003). Yoga Pour Les Enfants. Paris: Le Counier du Livre.

Leconte, C. (2005). Une si fragile attention. Cerveau et Psychol. 11, 36-40.

Lees, C., and Hopkins, J. (2013). Effect of aerobic exercise on cognition, academic achievement, and psychosocial function in children: a systematic review of 
randomized control trials. Prev. Chronic Dis. 10:E174. doi: 10.5888/pcd10. 130010

Ludyga, S., Gerber, M., Brand, S., Holsboer-Trachsler, E., and Pühse, U. (2016). Acute effects of moderate aerobic exercise on specific aspects of executive function in different age and fitness groups: a meta-analysis. Psychophysiology 53, 1611-1626. doi: 10.1111/psyp.12736

MacCobb, S., Fitzgerald, B., Lanigan-O'Keefe, C., Irwin, N., and Mellerick, N. (2014). Students with social, emotional, and behavioural difficulties: the Alert Program trial in post-primary schools. J. Occup. Ther. Sch. Early Interv. 7, 106-119. doi: 10.1080/19411243.2014.930606

Mak, C., Whittingham, K., Cunnington, R., and Boyd, R. N. (2018). Effect of mindfulness yoga programme MiYoga on attention, behaviour, and physical outcomes in cerebral palsy: a randomized controlled trial. Dev. Med. Child Neurol. 60, 922-932. doi: 10.1111/dmcn.13923

Maldarelli, J. E., Kahrs, B. A., Hunt, S. C., and Lockman, J. J. (2015). Development of early handwriting: visual-motor control during letter copying. Dev Psychol. 51, 879-888. doi: 10.1037/a0039424

Manjunath, N. K., and Telles, S. (2004). Spatial and verbal memory test scores following yoga and fine arts camps for school children. Indian J. Physiol. Pharmacol. 48, 353-356.

Matlin, M. (2009). Cognition. Hoboken, NJ: John Wiley \& Sons, Inc.

McClelland, M. M., Acock, A. C., Piccinin, A., Rhea, S. A., and Stallings, M. C. (2013). Relations between preschool attention span-persistence and age 25 educational outcomes. Early Child Res. Q. 28, 314-324. doi: 10.1016/j.ecresq. 2012.07.008

Miyake, A., Friedman, N. P., Emerson, M. J., Witzki, A. H., Howerter, A., and Wager, T. D. (2000). The unity and diversity of executive functions and their contributions to complex "frontal lobe" tasks: a latent variable analysis. Cogn. Psychol. 41, 49-100. doi: 10.1006/cogp.1999.0734

Noggle, J., Steiner, N. J., Minami, T., and Khalsa, S. B. S. (2012). Benefits of yoga for psychosocial well-being in a US high school curriculum: a preliminary randomized controlled trial jessica. J. Dev. Behav. Pediatr. 33, 193-201. doi: 10.1097/DBP.0b013e31824afdc4

Oberer, N., Gashaj, V., and Roebers, C. M. (2018). Executive functions, visualmotor coordination, physical fitness and academic achievement: longitudinal relations in typically developing children. Hum. Mov. Sci. 58, 69-79. doi: 10. 1016/j.humov.2018.01.003

Ortega, F. B., Ruiz, J. R., Castillo, M. J., and Sjöström, M. (2008). Physical fitness in childhood and adolescence: a powerful marker of health. Int. J. Obes. 32, 1-11. doi: $10.1038 /$ sj.ijo.0803774

Owen, K. B., Parker, P. D., Van Zanden, B., Macmillan, F., Astell-Burt, T., and Lonsdale, C. (2016). Physical activity and school engagement in youth: a systematic review and meta-analysis. Educ. Psychol. 51, 129-145. doi: 10.1080/ 00461520.2016 .1151793

Paour, J. L., and Cèbes, S. (2001). L'éducation cognitive à l'école maternelle: pourquoi, comment, avec quels effets? Revue De Psychologie De L'éducation. 3 , 86-111.

Peck, H. L., Kehle, T. J., Bray, M. A., and Theodore, L. A. (2005). Yoga as an intervention for children with attention problems. Sch. Psychol. Rev. 34, 415-424.

Perry, J. C., Liu, X., and Pabian, Y. (2010). School engagement as a mediator of academic performance among urban youth: the role of career preparation, parental career support, and teacher support. Couns. Psychol. 38, 269-295. doi: $10.1177 / 0011000009349272$

Purohit, S. P., and Pradhan, B. (2016). Effect of yoga program on executive functions of adolescents dwelling in an orphan home: a randomized controlled study. J. Tradit. Complement Med. 7, 99-105. doi: 10.1016/j.jtcme.2016. 03.001

Richardson, J. T. E. (2011). Eta squared and partial eta squared as measures of effect size in educational research. Educ. Res. Rev. 6, 135-147. doi: 10.1016/j.edurev. 2010.12.001
Rosen, L., French, A., and Sullivan, G. (2015). Complementary, holistic, and integrative medicine. Yoga Pediatr. Rev. 36, 468-474. doi: 10.1542/pir.3610-468

Rossner, M. Z. (1995). Yoga, Un Nouvel Espoir Pour Les Enfants En Détresse. Saint Zénon, QC: Louise Courteau.

Sandford, R., Duncombe, R., Mason, C., and Butler, C. (2015). Ability to be active: exploring children's active play in primary schools. Int. J. Play 4:2. doi: 10.1080/ 21594937.2015.1060569

Santangelo, L. (2012). Reducing stress in school-age girls through mindful yoga. J. Pediatr. Health Care 26, 45-56. doi: 10.1016/j.pedhc.2011.01.002

Sattelmair, J., and Ratey, J. (2009). Physically active play and cognition: an academic matter? Am. J. Play 1, 365-374.

Schaeffer, D. J., Krafft, C. E., Schwarz, N. F., Chi, L., Rodrigue, A. L., Pierce, J. E., et al. (2014). An 8-month exercise intervention alters frontotemporal white matter integrity in overweight children. Psychophysiology 51, 728-733. doi: $10.1111 /$ psyp. 12227

Schmidt, M., Jäger, K., Egger, F., Roebers, C. M., and Conzelmann, A. (2015). Cognitively engaging chronic physical activity, but not aerobic exercise, affects executive functions in primary school children: a group-randomized controlled trial. J. Sport Exerc. Psychol. 37, 575-591. doi: 10.1123/jsep.20150069

Sibley, B. A., and Etnier, J. L. (2003). The relationship between physical activity and cognition in children: a meta-analysis. Pediatr. Exerc. Sci. 15, 243-256. doi: $10.1123 /$ pes.15.3.243

Singh, A., Saliasi, E., van den Berg, V., Uijtdewilligen, L., de Groot, R. H. M., Jolles, J., et al. (2018). Effects of physical activity interventions on cognitive and academic performance in children and adolescents: a novel combination of a systematic review and recommendations from an expert panel. Br. J. Sports Med. doi: 10.1136/bjsports-2017-098136 [Epub ahead of print].

Singh, A., Uijtdewilligen, L., Twisk, J. W. R., Van Mechelen, W., and Chinapaw, M. J. M. (2012). Physical activity and performance at school: a systematic review of the literature including a methodological quality assessment. Arch. Pediatr. Adolesc. Med. 166, 49-55. doi: 10.1001/archpediatrics.2011.716

Taimini, I. (2005). The Science of Yoga. Madras: The Theosophical Publishing House.

Telles, S., Hanumanthaiah, B. H., Nagarathna, R., and Nagendra, H. R. (1993). Improvement in static motor performance following yogic training of school children. Percept. Mot. Skills 76, 1264-1266. doi: 10.2466/pms.1993.76. 3c. 1264

Verburgh, L., Königs, M., Scherder, E. J., and Oosterlaan, J. (2014). Physical exercise and executive functions in preadolescent children, adolescents and young adults: a meta-analysis. Br. J. Sports Med. 48, 973-979. doi: 10.1136/ bjsports-2012-091441

Verma, A., Uddhav, S., Ghanshyam Thakur, S., Devarao, D., Ranjit, K., and Bhogal, S. (2014). The effect of yoga practices on cognitive development in rural residential school children in India. Natl. J. Lab. Med. 3, 15-19.

World Medical Association (2013). Declaration of helsinki: ethical principles for medical research involving human subjects. JAMA 310, 2191-2194. doi: 10. 1001/jama.2013.281053

Conflict of Interest Statement: The authors declare that the research was conducted in the absence of any commercial or financial relationships that could be construed as a potential conflict of interest.

Copyright (c) 2019 Jarraya, Wagner, Jarraya and Engel. This is an open-access article distributed under the terms of the Creative Commons Attribution License (CC BY). The use, distribution or reproduction in other forums is permitted, provided the original author(s) and the copyright owner(s) are credited and that the original publication in this journal is cited, in accordance with accepted academic practice. No use, distribution or reproduction is permitted which does not comply with these terms. 